EVS25

Shenzhen, China, Nov 5-9, 2010

\title{
Load sharing control of dual energy storage power system in heavy duty series hybrid vehicles
}

\author{
Jukka Halme $^{1}$, Matti Liukkonen ${ }^{2}$, Jussi Suomela ${ }^{1}$ \\ ${ }^{1}$ Department of Automation and Systems Technology, Aalto University, Otaniementie 17, Espoo, 00076 Aalto \\ Finland, E-mail: johalme@cc.hut.fi \\ ${ }^{2}$ Department of Electrical Engineering, Aalto University, Otakaari 5, Espoo, 00076 Aalto Finland \\ E-mail: matti.j.liukkonen@tkk.fi
}

\begin{abstract}
Heavy duty off-road vehicle (HDOR) duty cycles are very different than passenger car cycles. HDOR duty cycles are characterized by heavy transient loads and highly varying constant power demands. Straddle carriers and mine loaders can operate 20 hours per day while cars are most of the time idle. Batteries and supercapacitors have different qualities in terms of power and energy density and cyclic life time. Hybridization of HDOR driveline reduces fuel consumption and contributes to cleaner workspace environment due to reduced emission. This paper presents new load sharing control method for battery \& supercapacitor series hybrid heavy-duty off-road vehicle. Both energy storages have separate DC/DCconverters. Control strategy ensures that both energy storages are used optimally based on their characteristic strengths. Implications of this control strategy are reduced consumption and more importantly improved battery lifetime. Control strategy is presented; simulation results for control performance are presented and discussed.
\end{abstract}

Keywords - Heavy-duty, Energy management, Power flow, Battery, Super capacitor

\section{Introduction}

Heavy duty off-road work machine manufacturers are becoming more interested in alternative power train solutions mainly for the same reasons that car manufacturers have, increasing running costs due oil price trends and tightening emission regulations. In case of mine loaders, driver for hybridization is also direct reduction of emissions themselves.

Batteries and supercapacitors can be used to good effect in achieving in optimizing energy consumption of vehicles. They enable downsizing of internal combustion engine (ICE). Batteries and supercapacitors have very different characteristics in energy and power density but also in their cyclic life. Inclusion of both high energy density lithium- ion batteries and high power density supercapacitors in the power system enables optimal power request response and improves efficiency of the power system. This however requires independent controllability of energy storages. In this paper lithium-ion battery pack and supercapacitor module have own buck-boost dc/dcconverters which enable full controllability independent of dc-link voltage.

Use rate of HDOR work machine is very high. HDOR vehicle duty cycles have transient and heavy power demands. In hybrid HDOW vehicles this means that unsupervised battery usage during the duty cycle causes battery degradation and therefore it is serious problem for battery lifecycle [1]. In this paper load current sharing control strategy is proposed. In this control strategy ICE 
produces mean load power on selected high efficiency operating points. Supercapacitor module is used to produce power to cover transient power demands. Battery pack is used to produce power along supercapacitor when demand for power exceeds transient time scale.

To prolong battery lifetime, battery usage strategy has to be considered carefully. In multi energy storage systems, batteries benefit from rest periods when cooling of the cells takes place $[2,4]$. Internal resistance of cells increases with age due to chemical degradation [3]. Internal resistance increase when state of charge (SoC) decreases [3]. It is also observed that high load current increases internal resistance and therefore decreases battery energy efficiency $[2,4,5]$. This implies that high current loads should be associated with energy storages that have high power density when energy storage characteristics and profiles are asymmetric [6]. It is also observed that efficiency of charging process is sensitive to pulsing load charge current [7]. A capacity loss phenomenon is also associated with temperature [8] according to Arrhenius law. Capacity loss is greater at high states of charge [8].

Considering arguments given above, battery control strategy for prolonging battery lifetime and maximizing efficiency can be designed and will be presented below in this paper.

\section{System Description}

In the context of this paper load sharing control method is studied using two different case studies. Both cases present typical load cycles for those types of heavy-duty off-road vehicles. Study method is simulation study. Both cases use identical energy storage topology that is shown in figure 1 . Symbol of electric motor represents all energy consumers in the system including traction motors and auxiliary actuators.

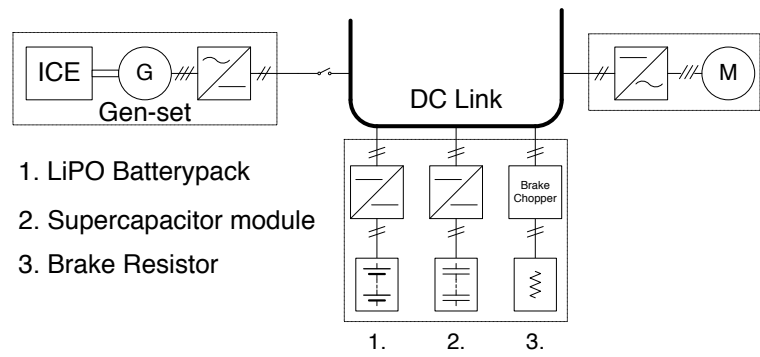

Energy storages shown in figure 1 are described in detail below. Although ICE is different in mine loader and straddle carrier cases, load power of duty cycles are scaled so that they both represent 134 $\mathrm{kW}$ diesel engines.

\section{Supercapacitor module:}

\author{
Maxwell BOOSTCAP BMOD0018 P390 \\ Voltage, nominal [Vdc] 390 \\ Voltage, maximum [Vdc] 394 \\ Capacitance, nominal [F] 17.8 \\ $\mathrm{DC} \operatorname{ESR}[\mathrm{m} \Omega] 65.0$ \\ Energy [Wh] 282 \\ Current limit, constant [A] 150 \\ Current limit, maximum [A] 950
}

\section{Battery pack:}

98 series connected Kokam SLPB 100216216H

lithium-ion polymer cells

Capacitance [Ah] 40.0

Voltage, nominal [Vdc] 362.6

Charge current, constant [A] 80

Discharge current, constant [A] 200

Discharge current, pulse [A] 400

Voltage, minimum [V] 2.7

Lifecycle estimate [@ 80\% DOD] > 1200 cycles

\subsection{Case study: Mine Loader}

First case study is about mine loader that has unloaded mass of $13875 \mathrm{~kg}$ and its maximum payload is $4090 \mathrm{~kg}$. ICE is naturally aspirant $90 \mathrm{~kW}$ diesel engine. Diesel engine model that has been verified [12] is model of $134 \mathrm{~kW}$ diesel engine. Therefore load power was multiplied with 1.5 to scale with $90 \mathrm{~kW}$ engine. Overall presentation of duty cycle is presented in figure 2 . Mine loader starts at dumping spot. After a short 4 percent upslope mine loader descents towards payload pickup point. On average, down slope is 12 percent. After down slope mine loader proceeds to pickup point without inclination. After payload pickup it returns to dump off point using exactly same route.

Figure 1: Series hybrid topology 


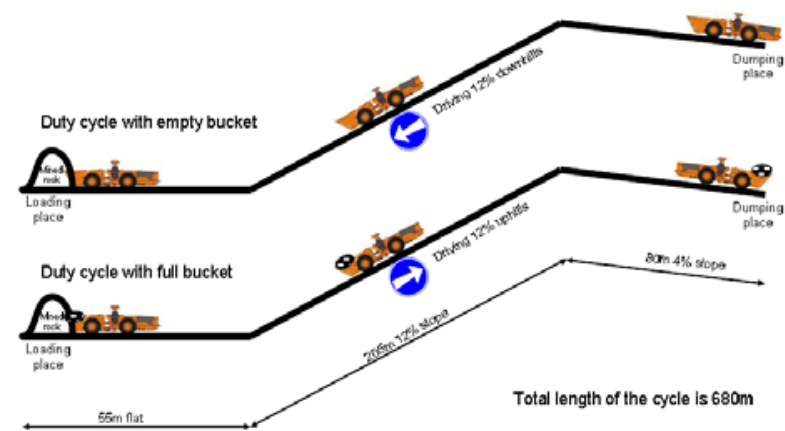

Figure 2: Load cycle overall presentation

Actual duty cycle of conventional power train mine loader with hydraulic bucket actuators was measured and time variant power requirements were acquired. Measured power requirement represents power of traction motors and does not include hydraulic power consumption of bucket. This is presented in figure 3 and used as load in simulation model.

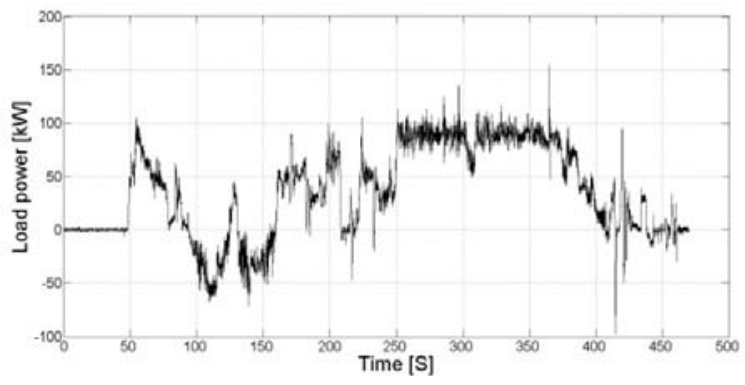

Figure 3: Mine loader load power

\subsection{Case Study: Straddle Carrier}

Second case study is about hybrid electric straddle carrier. Primary power producer, ICE, in this case is scaled to $134 \mathrm{~kW}$ diesel engine due to verified simulation model. Duty cycle was measured with straddle carrier that had diesel-electric power train. Duty cycle presented in figure 4 consists of following phases:

1. Drive to 25 ton container waiting for pickup

2. Pickup container

3. Drive to drop-off point

4. Drop-off container

5. Drive to second 25 ton container waiting for pickup

6. Pickup second container

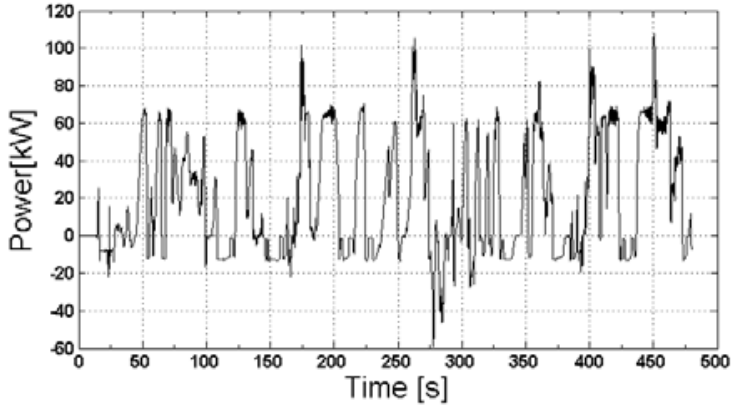

Figure 4: Straddle carrier duty cycle

\section{Simulation model}

Series hybrid electric work machine model was modeled using Matlab-Simulink by Mathworks [9].Modeling principle was to model actions and events at functional system frequency level of 20 $\mathrm{Hz}$. With this bandwidth energy management and power flow control can be designed but no information about detailed actions of power electronic components or switching frequency can be attained.

The model is backward model where premeasured load power, representing all power consumers in the system, is extracted from dc-link. Supercapacitor module is based on equivalent series resistance where capacitance varies as a function of supercapacitor voltage and current. Battery model is based on Mathworks battery model [10]. State of charge of the battery is calculated as follows:

$$
\operatorname{SOC}_{\text {batt }}=\frac{100\left(1-\frac{1}{Q} \int_{0}^{t} i(t) d t\right)}{100}
$$

Supercapacitor state of charge is calculated as follows:

$$
S O C_{s c}=\frac{U_{s c}}{U_{s c, \max }}
$$

Parameters for battery model were attained from constant current charge and discharge measurements. Diesel engine and generator models are based on measurements. Detailed description about simulation model and its validation is discussed in "Validation of quasi-static Series Hybrid Electric Vehicle Simulation model" paper [12].

\section{Load Sharing control method}

Designing control strategy for HDOR vehicle differs from passenger car control strategy due to differences in duty cycles. HDOR duty cycles are in general repetitive with power heavy transients. This 
creates constraints for controller design but repetitiveness also means predictability which can be used as an asset in controller design. Controller design has hierarchical constraint structure, where simulation targets are given priority [13]. Failure to hit targets of higher priority, nulls meaningfulness of hitting targets of lower priority.

Independent of control method or system platform, three general simulation targets can be defined:

1. Dc-link is kept stable in all phases of operation

2. Vehicle is able to complete its duty cycle

3. Energy produced by ICE is minimized

4. Recovered regenerative energy is maximized

Stability of dc-link in series hybrid vehicles is the most important control target. In this paper dc-link voltage is kept at $650 \pm 50$ volts. Vehicle must be able to provide at least as good performance as vehicles with conventional power train. Since diesel engine produces most of the power during the duty cycle, it is reasonable to target minimization of power produced by diesel engine. This has obvious implications on energy efficiency of the whole system.

After general control targets have been defined, further control method specific control targets can be defined. Load sharing control aims to optimize battery usage so that effect of use to battery lifetime is minimal without compromising system efficiency. This means that battery usage is optimized using supercapacitor to buffer powers system in transient loads.

\subsection{Gen-set control}

Generator is connected to diesel engine torque axis mechanically. This means that diesel engine's revolutions per minute (rpm) range of $1000 \mathrm{rpm}-$ $2100 \mathrm{rpm}$ is the same for the generator. Since the diesel engine is the primary power source for hybrid power train, operating strategy of the diesel engine has a major impact on total energy efficiency of the hybrid train. ICE is controlled using fixed operating points. These operating points were chosen using following method. First, histogram of power demands of characteristic duty cycle was plotted. Of this histogram, five characteristic power sectors of positive power values were chosen. Power demands of these sectors were the translated into fuel consumption optimal spots in speed - torque graph. Figure 5 shows positive power demand histogram of mine loader duty cycle and Table 1 shows how this information is translated into ICE speed references. Respectively figure 6 and table 2 present these for straddle carrier case. With this method, ICE operates on optimal operating points satisfying mean power demand of each power sectors. Negative power demands contribute to regenerative energy supply and not to power consumption. When regenerative energy is available, diesel engine is given minimum speed reference value of $1000 \mathrm{rpm}$ :

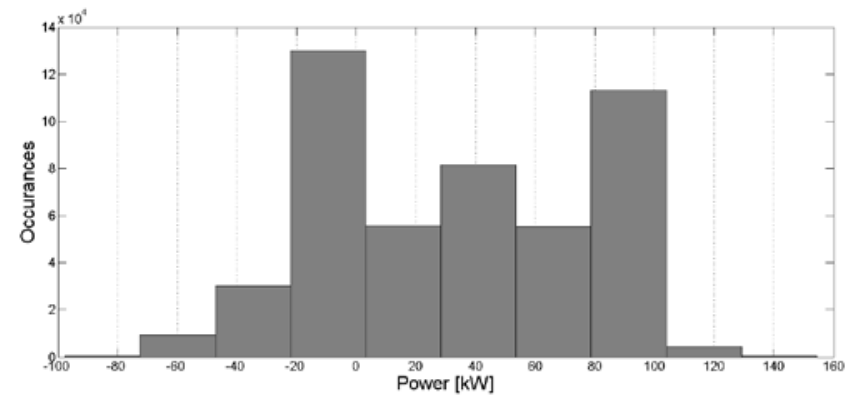

Figure 5: Mine loader power histogram

Table 1: Mine loader ICE speed reference values and respective load power values

\begin{tabular}{|c|c|}
\hline $\begin{array}{c}\text { Mine loader power } \\
\text { Demand }[\mathbf{k W}]\end{array}$ & $\begin{array}{c}\text { Mine loader, ICE speed } \\
\text { reference }[\mathbf{r p m}]\end{array}$ \\
\hline $0=<$ & 1000 \\
\hline$>10$ & 1200 \\
\hline$>30$ & 1400 \\
\hline$>55$ & 1700 \\
\hline$>80$ & 2100 \\
\hline
\end{tabular}

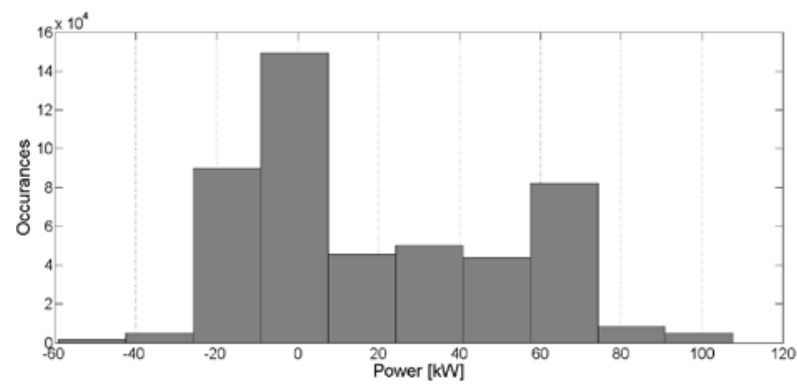

Figure 6: Straddle carrier power histogram 


\begin{tabular}{|c|c|}
\hline $\begin{array}{c}\text { Table 2: Straddle carrier ICE speed reference } \\
\text { values and respective load power values }\end{array}$ \\
\hline $\begin{array}{c}\text { Straddle carrier } \\
\text { power } \\
\text { Demand }[\mathbf{k W}]\end{array}$ & $\begin{array}{c}\text { Straddle carrier, ICE } \\
\text { speed reference [rpm] }\end{array}$ \\
\hline $0=<$ & 1000 \\
\hline$>10$ & 1200 \\
\hline$>30$ & 1400 \\
\hline$>57$ & 1700 \\
\hline$>75$ & 2100 \\
\hline
\end{tabular}

\subsection{Energy storage control}

After power produced by ICE is calculated, energy storage power demands are calculated using 20 millisecond low-pass power filter [11]. Implemented low-pass filter concept is presented in figure 7 below. Load current is then divided into two parts where supercapacitor provides system power to meet transient power loads. More constant part of power demand is covered by battery pack. This enables optimal usage of both energy storages characteristics, high power density of supercapacitor and high energy density of the battery pack. Calculated current reference values for both energy storages are transmitted to current controlled bi-directional dc/dc-converters. Energy storage control strategies are more charge sustaining than charge depleting. Control strategy should try to ensure that work machine can operate decent length work shifts without need to recharge. Charge and discharge control is described in detail below.

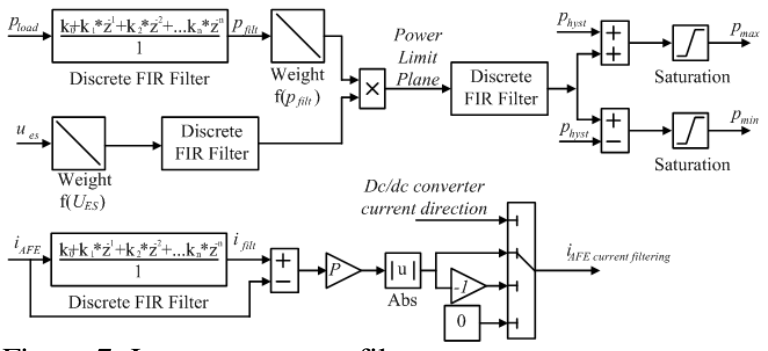

Figure 7: Low-pass power filter

\subsection{Charge current control}

Charge current reference is controlled in six different states that define all possible operation modes. Four of the modes are triggered by examining state of charges of battery pack and supercapacitor. Fifth and sixth states are triggered by high voltage values of dc-link. Current reference calculations for these states are given below. State trigger conditions are given in the heading of the state.

State 1: $\mathrm{SOC}_{\mathrm{sc}}=1 \& \& \mathrm{SOC}_{\mathrm{batt}}<1 \& \& \mathrm{U}_{\mathrm{dc}}<680$

Iref $_{\mathrm{sc}}=0$

Iref $_{\text {batt }}=\frac{\sum_{j=1}^{n} \text { Iref }}{n}$,

where $\mathrm{n}=500$ and Iref $_{\text {batt }}$ is restricted

$[0,200]$

State 2: $\mathrm{SOC}_{\mathrm{sc}}<1 \& \& \mathrm{SOC}_{\text {batt }}=1 \& \& \mathrm{U}_{\mathrm{dc}}<680$

Iref $_{\mathrm{sc}}=$ Iref

Iref $_{\text {batt }}=0$

State 3: $\mathrm{SOC}_{\mathrm{sc}}<1 \& \& \mathrm{SOC}_{\mathrm{batt}}<1 \& \& \mathrm{U}_{\mathrm{dc}}<680$

Iref $_{\text {sc }}=$ Iref - Iref $_{\text {batt }}$

Iref $_{\text {batt }}=\left(1-\mathrm{SOC}_{\text {batt }}\right) *$ Iref,

where $\operatorname{Iref}_{\text {batt }}$ is restricted $[0,80]$

State 4: $\mathrm{SOC}_{\mathrm{sc}}=1 \& \& \mathrm{SOC}_{\mathrm{batt}}=1$

Iref $_{\mathrm{sc}}=0$

Iref $_{\text {batt }}=0$

State 5: $\mathrm{U}_{\mathrm{dc}}>680 \& \& \mathrm{SOC}_{\mathrm{sc}}<1$

$\operatorname{Iref}_{\mathrm{sc}}=2 *\left(\mathrm{U}_{\mathrm{dc}}(\mathrm{t})-680\right)+100$

Iref $_{\text {batt }}=0$

State 6: $\mathrm{U}_{\mathrm{dc}}>680 \& \& \mathrm{SOC}_{\mathrm{batt}}<1 \& \& \mathrm{SOC}_{\mathrm{sc}}=1$

Iref $_{\mathrm{sc}}=0$

$\operatorname{Iref}_{\text {batt }}=2 *\left(\mathrm{U}_{\mathrm{dc}}(\mathrm{t})-680\right)+100$

Where:

Iref - total current demand from energy storages [A]

Iref $_{\mathrm{sc}}-$ Current reference for super capacitor dc/dcconverter $[\mathrm{A}]$

Iref $_{\text {batt }}$ - Current reference for super capacitor $\mathrm{dc} / \mathrm{dc}$-converter $[\mathrm{A}]$

$\mathrm{SOC}_{\mathrm{sc}}$-State of Charge, Super capacitor $[0,1]$

$\mathrm{SOC}_{\text {batt }}$ - State of Charge, Battery pack $[0,1]$

$\mathrm{U}_{\mathrm{dc}}-\mathrm{DC}$-link voltage $[\mathrm{V}]$

State 1 represents situation when super capacitor state of charge has reached its maximum. To prevent power surges to battery, current reference to battery is smoothed using 500 sample moving average. Since simulation time step is 1 millisecond, 500 sample smoothing translates into0.5 second smoothing. Purpose of this is to prevent high transient loads to battery pack. In state 2 , battery has reached maximum state of charge. In this case whole Iref value is current reference to supercapacitor dc/dc-converter. This can be 
justified with supercapacitors excellent cyclic and transient load endurance. State 3 represents the most common operating state where both energy storages are able to recover regenerative energy. To prevent battery pack absorbing all regenerative energy and to keep supercapacitors state of charge in reasonable value, current reference for battery pack dc/dc-converter is limited relative to its state of charge. Maximum battery pack current reference is limited to 80 amperes due to Kokam cell specification. States 5 and 6 are fallback states for high dc-link voltages. These states try to recover as much regenerative energy as possible. If dc-link voltage exceeds value of 700 volts, brake chopper activates and excess power is conducted to brake resistor.

\subsection{Discharge current control}

Calculation of discharge current references for energy storage $\mathrm{dc} / \mathrm{dc}$-converters is divided into four different states that define all possible conditions. Supercapacitor minimum state of charge is limited to 0.5 due to efficiency reasons. Battery pack minimum is limited to 0.2 to avoid deep cycling.

State 1: $\mathrm{SOC}_{\mathrm{sc}}<0.5 \& \& \mathrm{SOC}_{\text {batt }}>0.2$

$$
\begin{aligned}
& \text { Iref }_{\mathrm{sc}}=0 \\
& \text { Iref }_{\text {batt }}=\frac{\sum_{j=1}^{n} \text { Iref }}{n}, \\
& \text { where } \mathrm{n}=500 \text { and Iref } \mathrm{f}_{\text {batt }} \text { is restricted }
\end{aligned}
$$

State 2: $\mathrm{SOC}_{\mathrm{sc}}>0.5 \& \& \mathrm{SOC}_{\text {batt }}<0.2$

$$
\begin{aligned}
& \operatorname{Iref}_{\mathrm{sc}}=\text { Iref } \\
& \operatorname{Iref}_{\text {batt }}=0
\end{aligned}
$$

State 3: $\mathrm{SOC}_{\mathrm{sc}}>0.5 \& \& \mathrm{SOC}_{\text {batt }}>0.2$

$$
\begin{aligned}
& \operatorname{Iref}_{\mathrm{sc}}={\text { Iref }- \text { Iref }_{\text {batt }}} \\
& \text { If Iref }>20 \\
& \qquad \operatorname{Iref}_{\text {batt }}=\left(\frac{\left.\sum_{j=1}^{n} \text { Iref }^{n}\right) * \mathrm{SOC}_{\text {batt }},}{\text { where }=500 \text { and Iref }}\right. \text { batt is restricted }
\end{aligned}
$$$$
[0,120]
$$

State 4: $\mathrm{SOC}_{\mathrm{sc}}<0.5 \& \& \mathrm{SOC}_{\text {batt }}<0.2$

$$
\begin{aligned}
& \operatorname{Iref}_{\mathrm{sc}}=0 \\
& \text { Iref }_{\text {batt }}=0
\end{aligned}
$$

State 1 represents situation where supercapacitor is depleted. To avoid unnecessary transient loads battery pack dc/dc-converter current reference value is smoothened with $500 \mathrm{~ms}$ moving average. In state 2 current demand is directly transferred to supercapacitor current reference. In discharge situations state 3 represents situation where energy storages are usable. Supercapacitor module is assigned all load demands below 20 amperes. Load demands above this are smoothened with $500 \mathrm{~ms}$ moving average. State 4 represents situation where control strategy has failed since both energy storages are depleted and work machine should be assigned to idle state to recharge energy storages.

\section{Simulation Results and analysis}

\subsection{Mine loader simulation results}

In figures 8-10, results of simulation of mine loader are presented. Figure 8 shows that a dc-link stability criterion is met so that voltages are within accepted interval of $600-700$ volts. In the middle graph of figure 8 it can be seen that control method executes intended energy storage behavior. Battery pack provides more constant parts of the power demand and supercapacitor provides power for more transient parts of the load. In figure 9, voltages and state of charges of both energy storages are presented. State of charge of battery drops from initial value of 0.8 to 0.74 and supercapacitor state of charge drops from 0.85 to 0.72 . A 0.06 drop in battery SOC equals $0.889 \mathrm{kWh}$ energy drop in battery. Since power consumption in duty cycles is larger than amount of regenerative energy available, completely charge sustaining control is not feasible. These state of charge drops seem to imply that mine loader would be able to execute multiple duty cycles without need to pause operation to recharge energy storages, that was the original idea of the control strategy described above. Figure 10 represents an efficiency map of ICE. Operating points of the ICE in speed (rpm) torque $(\mathrm{Nm})$ graph are plotted in relation to amount of fuel required to produce required energy $(\mathrm{g} / \mathrm{kWh})$. Blue crosses in the graph are actual operating points during the duty cycle. It can be seen that most of the operating points are located in feasible fuel consumption area. At low speeds, $1000-1200 \mathrm{rpm}$, operating points are located at slightly less effective efficiency area. 


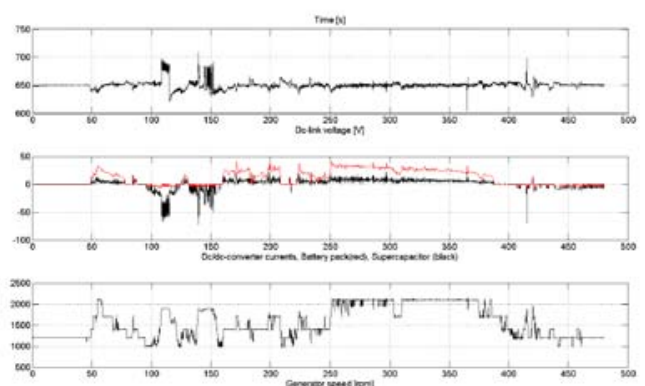

Figure 8: Mine loader simulation results part 1
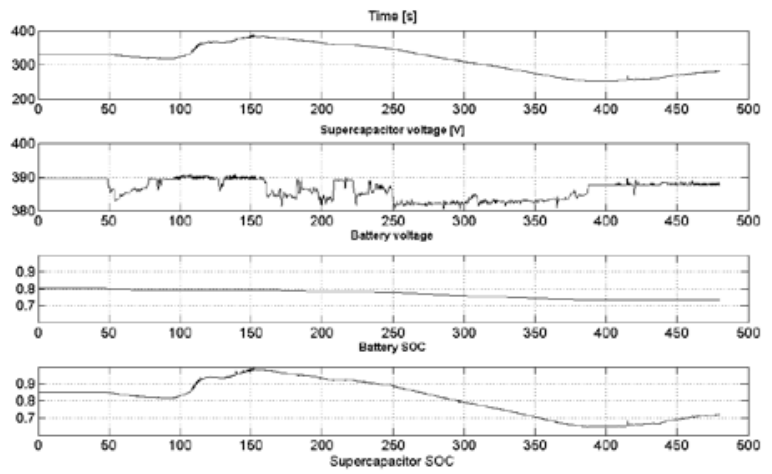

Figure 9: Mine loader simulation results part 2

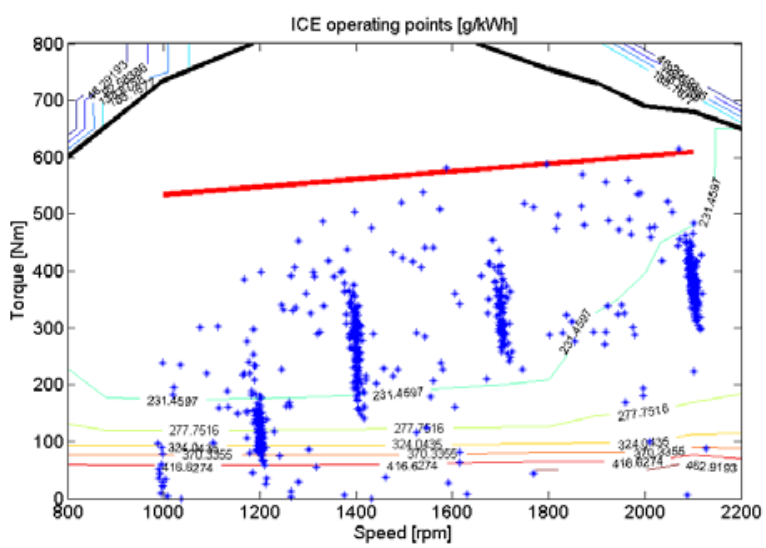

Figure 10: Mine loader ICE operating points

Simulation was also run with energy storages disconnected representing diesel electric power train. Numerical results compared to hybrid electric are presented in table 3 below. Energy bias refers to energy loss of battery in regard of initial and final SOC of the battery pack. During the diesel electric simulation, dc-link voltage collapsed to 400 volts once during heavy transient load. Therefore numerical values are presented for comparative purposes that give estimate about benefits of hybridization. It can be clearly seen from table 3 that usage of energy storages and presented control method, smaller ICE can be used and average power and energy produced by ICE is reduced almost $20 \%$.

\begin{tabular}{|c|c|c|}
\hline $\begin{array}{l}\text { Table 3: Mine loader } \\
\text { numerical comparison of } \\
\text { hybrid electric and diesel } \\
\text { electric power trains }\end{array}$ & $\begin{array}{c}\text { Hybrid } \\
\text { electric }\end{array}$ & $\begin{array}{c}\text { Diesel } \\
\text { electric }\end{array}$ \\
\hline $\begin{array}{c}\text { Energy produced by ICE } \\
{[\mathrm{kWh}]}\end{array}$ & 5.26 & 6.54 \\
\hline $\begin{array}{c}\text { Maximum power produced } \\
\text { by ICE [kW] }\end{array}$ & 134.0 & 142.7 \\
\hline $\begin{array}{c}\text { Average power produced by } \\
\text { ICE [kW] }\end{array}$ & 39.43 & 49.03 \\
\hline Maximum load power [kW] & 122.5 & 122.5 \\
\hline Average load power [kW] & 34.47 & 34.47 \\
\hline $\begin{array}{c}\text { Energy bias of battery } \\
{[\mathrm{kWh}]}\end{array}$ & 0.889 & - \\
\hline
\end{tabular}

\subsection{Straddle carrier simulation results}

Figures 11-13 represent simulation results of hybrid electric straddle carrier. Figure 11 below shows that dc-link is kept stable during the load cycle and cooperation of energy storages works as intended as in case of mine loader. Figure 12 shows that battery state of charges drops from 0.8 to 0.77 and supercapacitor state of charge drops from 0.85 to 0.75 enabling execution multiple repetitive duty cycles without needing to pause for recharging. Battery energy loss due change in battery SOC is $0.444 \mathrm{kWh}$. Figure 13 represents ICE operating efficiency. Results resemble the ones from mine loader case as expected.
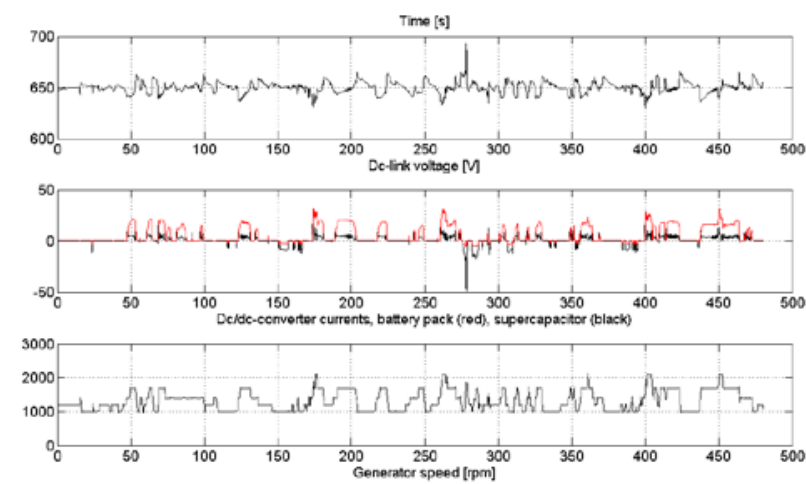

Figure 11: Straddle carrier simulation results part 1 


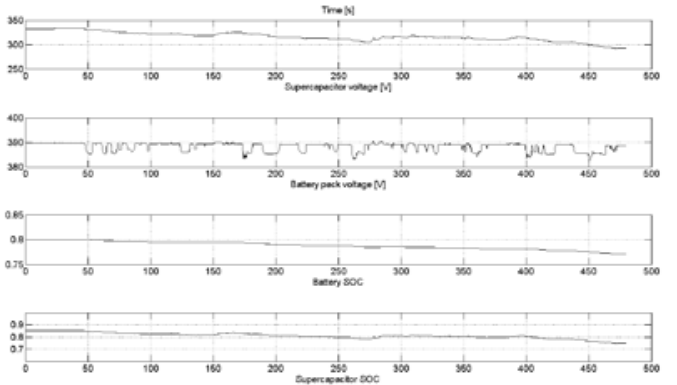

Figure 12: Straddle carrier simulation results part 2

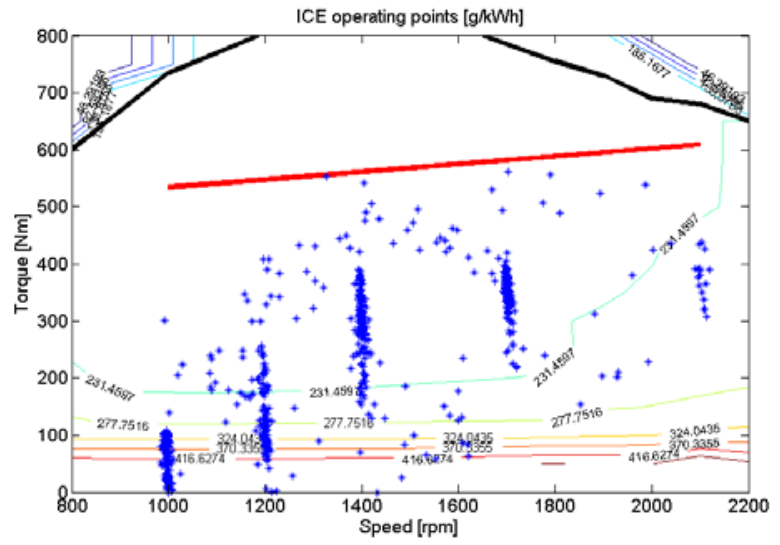

Figure 13: Straddle carrier ICE operating points

Straddle carrier simulations were also run without energy storages connected. Numerical comparisons with hybrid electric straddle carrier are shown below in table 4 . Energy and power production are reduced by $14 \%$.

\begin{tabular}{|c|c|c|}
\hline $\begin{array}{l}\text { Table 4: Straddle carrier } \\
\text { numerical comparison of } \\
\text { hybrid electric and diesel } \\
\text { electric power trains }\end{array}$ & $\begin{array}{l}\text { Hybrid } \\
\text { electric }\end{array}$ & $\begin{array}{c}\text { Diesel } \\
\text { electric }\end{array}$ \\
\hline $\begin{array}{c}\text { Energy produced by ICE } \\
\text { [kWh] }\end{array}$ & 3.72 & 4.29 \\
\hline $\begin{array}{c}\text { Maximum power produced } \\
\text { by ICE [kW] }\end{array}$ & 116.2 & 136.4 \\
\hline $\begin{array}{c}\text { Average power produced by } \\
\text { ICE [kW] }\end{array}$ & 27.92 & 32.16 \\
\hline Maximum load power [kW] & 107.6 & 107.6 \\
\hline Average load power [kW] & 19.56 & 32.16 \\
\hline $\begin{array}{c}\text { Energy bias of battery } \\
{[\mathrm{kWh}]}\end{array}$ & 0.444 & - \\
\hline
\end{tabular}

\section{Conclusions}

In this paper, novel rule-based dual energy storage series hybrid power train control method for heavy duty off-road vehicle was presented. This control method was implemented and its functionality was tested with two different work machine cases. Case studies imply that control strategy functions as designed meeting all the simulation targets planned beforehand. Hybridization and this control strategy leads to $20 \%$ reduced fuel consumption while meeting the relative charge sustaining criterion. To maintain charge sustaining principle and still reduce fuel consumption would require further and more intensive optimization of ICE operating points. Both, constant speed reference ICE control and continuously variable speed reference ICE control should be investigated.

Mobile work machines have very different duty cycles compared to each other. Presented general dual energy storage control method provides a solid base for further optimization. Optimizing the sizing of the energy storages and control method parameters to suit each case will provide more reduction in fuel consumption and increase in total efficiency of the energy system. These case dependant optimizations are target of the future work.

\section{Acknowledgements:}

This study has been carried out in HybDrive, TopDrive and HybLab projects financed by the Finnish Funding Agency for Technology and Innovations (Tekes) and Multidisciplinary Institute of Digitalization and Energy (MIDE) of Aalto University School of Science and Technology, respectively.

\section{References}

[1] N. Omar, Effectiveness evaluation of a Supercapacitor-battery parallel combination for Hybrid Heavy Lift Trucks, EVS 24 conference proceedings, 2008.

[2]. G. Castelli, Current-controlled policies for batterydriven dynamic power management, IEEE Design \& Test, Volume 18, Issue 2, 2001

[3] M. Coleman, An Improved Battery Characterization Method Using a Two-Pulse Load Test, IEEE Transactions on Energy Conversion, Vol. 23, No. 2, 2008

[4] J. Zhang, Modeling Discharge Behavior of Multicell Battery, Accepted for IEEE Transactions on Energy Conversion

[5] L. Benini, Discharge Current Steering for Battery Lifetime Optimization, IEEE Transactions on Computers,Vol.52, No. 8, 2003 
[6] Q. Wu, An Interleaved Dual-Battery Power Supply for Battery-Operated Electronics, IEEE Asia and South Pacific Design Automation Conference, Yokohama, Japan, pp. 387-390, January 2000

[7] W. Xiang, Analysis of Filter Circuit of DC Side in High-Frequency Current Transformer Based on Battery Performance,

Electrical Machines and Systems, 2005. ICEMS 2005. Proceedings of the Eighth International Conference on Vol. 2, 2005

[8] A. Ritchie, Recent developments and likely advances in lithium rechargeable batteries, Journal of Power Sources, Volume 136, Issue 2, 2004

[9] Mathworks webpage

http://www.mathworks.com/

[10] Mathworks battery model

http://www.mathworks.com/access/helpdesk/help/toolbo x/physmod/powersys/ref/battery.html

[11] M. Liukkonen, Low-pass Filtered Power-flow Control in Series Hybrid Electric Vehicle, EVS 24 conference proceedings, 2008

[12] M. Liukkonen, Validation of quasi-static Series Hybrid Electric Vehicle Simulation model, Accepted for IEEE VPPC 2010 conference.

[13] J. Halme, Power bus control for series hybrid heavy-duty vehicles, World Electric Vehicle Journal Vol. 3, 2009

\section{Author}

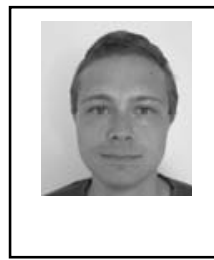

M.Sc, reserarcher, Jukka Halme Aalto University Otaniementie 17 ,00076 Aalto, Finland

Fax: +358947023308

Email: johalme@cc.hut.fi

$\mathrm{He}$ is researcher in laboratory of automation technology at Helsinki University of Technology. He received his M.Sc. (eng) in automation technology 2008. Since 2007 he has been working in research projects studying series hybrid technology and application to heavy-duty off-road vehicles and aims to write doctoral dissertation on energy optimization in hybrid off-road heavy duty vehicles.

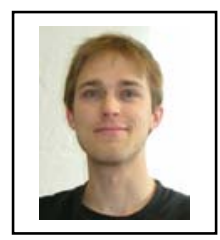

M.Sc, researcher. Matti Liukkonen Aalto University Otakaari 5, 00076 Aalto, Finland Fax: +358947022432

Email: matti.j.liukkonen@tkk.fi In 2008, he wrote his master's thesis about "Functional Simulations of Power Electronics Components in Hybrid machinery". Since then he has been working in work machine hybridization projects and aims write his doctoral theses in this topic.

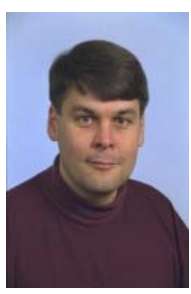

Prof. Jussi Suomela

Aalto University,

Otaniementie 17, 00076 Aalto, Finland

Tel: +358503377704

Fax: + 358947023308

E-mail: jussi.suomela@tkk.fi

Jussi Suomela received the M.Sc., Lic.Sc., and D.Sc. degrees from Helsinki University of Technology (TKK), Espoo, Finland, in 1992, 2001 and 2004, respectively. In the start of 2010 TKK became a part of new Aalto University. Suomela has worked in the University since 1991 in various positions. His main research areas are hybrid electric transmission in off-road mobile machines and field and service robotics. At the moment Suomela is professor of automation technology. 